Gut, 1983, 24, 1117-1125

\title{
Gastric emptying in normal subjects - a reproducible technique using a single scintillation camera and computer system
}

\author{
P J COLLINS, M HOROWITZ, D J COOK, P E HARDING, \\ AND D J C SHEARMAN \\ From the Division of Nuclear Medicine, Institute of Medical and Veterinary Science, Endocrine Unit, Royal \\ Adelaide Hospital and the Department of Medicine, University of Adelaide, Adelaide, South Australia
}

SUMMARY The gastric emptying of a mixed solid and liquid meal was assessed in 24 normal subjects using a single camera/computer system which allowed continuous monitoring of both solids and liquids. It was shown that variation in tissue attenuation caused by the changing depth of radionuclide within the stomach accounted for large errors in the measurement of gastric emptying (alteration in $50 \%$ emptying time of up to $65 \%$ ). A technique for the correction of attenuation is described which used factors derived from a lateral image of the stomach. In all subjects, solid emptying was slower than liquid emptying and was characterised by a delay (lag period) which was followed by linear emptying. Liquid emptying usually followed a single exponential pattern. The effect of physiological changes induced by increasing the calorie content of the liquid component of the meal was assessed by giving either water, $10 \%$ dextrose or $25 \%$ dextrose. Liquid emptying was slowed and the lag period of solid was prolonged as the calorie content increased. Reproducibility was assessed in 19 subjects. For the three groups studied (water, $10 \%$ dextrose, $25 \%$ dextrose) the day-to-day variation in gastric emptying was not significant for any measured parameter, while statistically significant differences were present in solid and liquid emptying between subjects and groups.

Radionuclide methods are being used increasingly to study the gastric emptying of both solid and liquid components of a meal and by these means disorders of gastric emptying and of the distribution of solid and liquid components of a meal within the stomach have been shown. ${ }^{1-8}$

Analysis of studies from different centres indicates inadequate information in two important areas. It has been recognised by some groups ${ }^{9} 10$ that the variation in depth of radionuclide within the stomach may result in a significant error in the measurement of gastric emptying if no attempt is made to correct for gamma ray attenuation by the patient's tissues. Previously reported correction techniques utilising either a dual probe rectilinear scanner ${ }^{10}$ or a single scintillation camera ${ }^{9}$ are

\footnotetext{
Address for correspondence: Professor D J C-Shearman, Department of Medicine. University of Adelaide. Royal Adelaide Hospital, Adelaide. South Australia $\mathbf{5 0 0 0 .}$

Received for publication 25 February 1983
}

effective but suffer from infrequent time sampling of the data. In the present study, a technique for the correction of attentuation is described which utilised a lateral image of the stomach and a single camera computer system, and enabled continuous monitoring of the emptying of solid (chicken liver labelled with technetium $99 \mathrm{~m}$ sulphur colloid ${ }^{4}$ $\left({ }^{99} \mathrm{~m}\right.$ Tc-SC)) and liquid (diethyltriaminepentaacetic acid labelled with indium $113 \mathrm{~m}^{2}\left({ }^{113 m} \mathrm{In}-\mathrm{DTPA}\right)$ ).

Many studies have failed to define the reproducibility of gastric emptying studies within individual patients. The present paper assesses reproducibility during physiological studies to determine the effect of increasing the calorie content of the liquid component of the meal.

\section{Methods}

PHANTOM STUDIES

Attenuation coefficients

These were obtained for ${ }^{99 \mathrm{~m}} \mathrm{Tc}(140 \mathrm{keV})$ and ${ }^{113 \mathrm{~m}} \mathrm{In}$ 
$(393 \mathrm{keV})$ by counting a $37 \mathrm{MBq}(1 \mathrm{mCi})$ source at various depths in a large water-bath placed on the collimator surface.

\section{Compton scatter}

A $250 \mathrm{ml}$ conical flask containing $37 \mathrm{MBq}(1 \mathrm{mCi})$ of ${ }^{99 \mathrm{~m}} \mathrm{Tc}$ in $200 \mathrm{ml}$ water was positioned $6 \mathrm{~cm}$ from the collimator surface in a water-bath and a 20 second image was taken in the ${ }^{99 \mathrm{~m}} \mathrm{Tc}$ window (image $\mathrm{A}$ ): 18 $\mathrm{MBq}(0.5 \mathrm{mCi})$ of ${ }^{113 \mathrm{~m}} \mathrm{In}$ was then added to the flask and 20 second images were taken in the ${ }^{99 \mathrm{~m}} \mathrm{Tc}$ and ${ }^{113 \mathrm{~m}}$ In windows. A region of interest obtained from image A was used for all three images. The increase in counts in the ${ }^{99 \mathrm{~m}} \mathrm{Tc}$ window resulting from the addition of ${ }^{113 \mathrm{~m}}$ In was expressed as a percentage of the counts in the ${ }^{113 \mathrm{~m}}$ In window.

PREPARATION OF SOLID MARKER AND LIQUID

MARKER

One gigabecquerel $(27 \mathrm{mCi})$ of ${ }^{99 \mathrm{~m}} \mathrm{Tc}-\mathrm{SC}$ was injected into a wing vein of a live chicken, as described by Meyer et al. ${ }^{4}$ After 20 minutes the chicken was killed and the liver removed. The amount of liver containing 37-55 MBq (1-1.5 mCi) of ${ }^{99 \mathrm{~m}} \mathrm{Tc}-\mathrm{SC}$ was mixed into $100 \mathrm{~g}$ ground beef and the resulting 'hamburger' cooked on a griller. The total calorie content of the solid meal $(25 \mathrm{~g}$ protein, $21 \mathrm{~g}$ fat) was approximately $270 \mathrm{kcal}(1 \cdot 13 \mathrm{Mj})$. The liquid marker was $18-28 \mathrm{MBq}(0.5-0.75 \mathrm{mCi})$ of $113 \mathrm{~m}$ In-DTPA mixed in $150 \mathrm{ml}$ of either water, $10 \%$ dextrose, or $25 \%$ dextrose. The whole body radiation dose was calculated to be approximately 400 microsieverts (40 mrad) for each study.

\section{SUBJECTS/GROUPS}

All subjects were non-smokers, on no medication and had no gastrointestinal disease. Informed consent was obtained and the study was approved by the Research Review Committee of the Royal Adelaide Hospital.

Group A comprised 11 subjects (seven men, four women) who received solid and water. In group B, seven subject (five men, two women) were given solid and $10 \%$ dextrose, and in group $\mathrm{C}$, six subjects (five men, one woman) received solid and $25 \%$ dextrose.

The mean age in each group was similar: group $\mathrm{A}$, 32 years (range 25-64 years); group B, 31 years (27-39 years); group C, 30 years (27-37 years). All subjects were within $20 \%$ of their ideal weight (mean $\pm \mathrm{SEM}-72 \pm 3 \mathrm{~kg}, 70 \pm 6 \mathrm{~kg}, 73 \pm 5 \mathrm{~kg}$, respectively).

The study was repeated within seven days in nine of group A, five of group B, and five of group C subjects to assess reproducibility.
PERFORMANCE OF TEST

The gastric emptying test was begun at 12.30 hours. Each subject had previously eaten a light standard breakfast at 07.30 hours. The study was performed in the sitting position with the detector behind the patient. A cross-shaped marker containing ${ }^{99 \mathrm{~m}} \mathrm{Tc}$ was taped to the subject's back to aid in correction for patient movement during the study. The subject ate the solid meal gradually over a five minute period and then drank the $150 \mathrm{ml}$ of liquid containing $113 \mathrm{~m}$ In-DTPA. Data collection commenced at the beginning of food ingestion. At 30 minute intervals, data acquisition was interrupted for five minutes to allow the subject to stand or sit away from the camera. Each study was continued for at least two hours.

\section{DATA ACQUISITION}

A scintillation camera (400 keV parallel-hole collimator) interfaced to a computer was used for data collection. The energy window alternated regularly between that of ${ }^{113 \mathrm{~m}} \mathrm{In}$ (393 keV) and ${ }^{99 \mathrm{~m}} \mathrm{Tc}$ (140 keV), using an automatic switching device. During the first 10 postcibal minutes, the energy window alternated every five seconds. Subsequently, this interval was increased to 50 seconds. The switching device placed switching 'marks' in the data stream to allow subsequent reconstruction into frame mode images. At the end of data acquisition, 3.7 MBq $(100 \mu \mathrm{Ci})$ of ${ }^{99 m}$ Tc-DTPA in $150 \mathrm{ml}$ water was given orally and a one minute left lateral image of the upper abdomen was taken.

DATA ANALYSIS

Frame mode reconstruction

The study comprised five list mode files. Each of these files was reformated to produce separate dynamic studies for the solid and liquid components. The dynamic studies were corrected for subject movement and realigned to a single reference point, using the ${ }^{99 \mathrm{~m}} \mathrm{Tc}$ marker. This facilitated determination of the region of interest. The solid study was corrected for ${ }^{113 \mathrm{~m}}$ In Compton scatter by subtracting a proportion of the ${ }^{113 \mathrm{~m}}$ In image from its corresponding ${ }^{99 \mathrm{~m}} \mathrm{Tc}$ image. Because the solid and liquid studies were stored alternatively, an image equal to the average of the two ${ }^{113 m}$ In images adjacent in time to the ${ }^{99 \mathrm{~m}} \mathrm{Tc}$ image was used for this correction.

\section{Attenuation correction factors}

Using the lateral image, the distance from the midpoint of the stomach to the collimator surface in $\mathrm{cm}\left(\mathrm{X}_{\mathrm{i}}\right)$ was calculated at all levels from the fundus to the pylorus (Fig. 1a). Two sets of line correction factors $\left(F_{i}\right)$ for the solid and liquid phases of the 


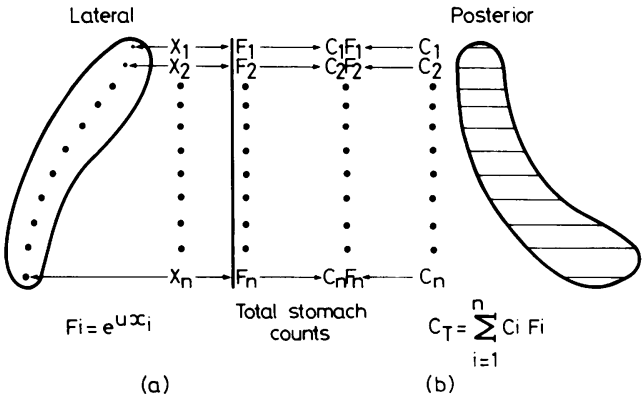

(a)

(b)

Fig. 1 Correction for tissue attenuation using a lateral image of the stomach. (a) Generation of correction factors $F_{i}=$ exponential $\left(\mu X_{i}\right)$ where $X_{i}$ is distance from mid-point of stomach to collimator surface and $\mu$ is attenuation coefficient. (b) Formation of the total stomach counts $C_{T}=\sum_{i=1}^{n} C_{i} F_{i}$

where $C_{i}$ is sum, and $F_{i}$ attenuation correction factor for line $i$.

study were generated $\left(F_{i}=\exp \left(\mu X_{i}\right)\right)$ using the appropriate attenuation coefficient $\mu$.

\section{Histogram generation}

Using the computer display, a region of interest was drawn to include the whole stomach, but excluding the small intestine. For each frame of the study, the total counts in the region of interest $\left(\mathrm{C}_{\mathrm{T}}\right)$ was the sum of the individual line sums which had been corrected for tissue attenuation $\left(\mathrm{C}_{\mathrm{i}} \mathrm{F}_{\mathrm{i}}\right)$ - that is,

$$
\mathrm{C}_{\mathrm{T}}=\sum_{\mathrm{i}=1}^{\mathrm{n}} \mathrm{C}_{\mathrm{i}} \mathrm{F}_{\mathrm{i}}
$$

(Fig. 1b). The histograms for the solid and liquid components of the meal (expressed as percentage of the total meal remaining within the stomach $v s$ time) were corrected for radionuclide decay and printed. The value for $100 \%$ retention of the meal was derived from the maximum count rate achieved in the first 20 minutes of the study.

Several parameters were derived from these histograms. For the solid component these parameters were: the lag period before onset of emptying, the time for $50 \%$ emptying $\left(\mathrm{T}_{50}\right)$ and the average rate of linear emptying (expressed as $\%$ /minute). For the liquid component, the $\mathrm{T}_{50}$ and the amount of tracer remaining at 10 minutes after ingestion were obtained. The linear emptying rate of solid was calculated from a straight line of best fit, drawn through the data points which followed the lag period.
STATISTICAL METHODS

Data were analysed using Student's $t$ test and linear regression analysis. The reproducibility of the technique was analysed using analysis of variance.

\section{Results}

PHANTOM STUDIES

The attenuation coefficients in tissue were $\mu=0 \cdot 12$ $\mathrm{cm}^{-1}$ for ${ }^{99 \mathrm{~m}} \mathrm{Tc}(140 \mathrm{keV})$ and $\mu=0.09 \mathrm{~cm}^{-1}$ for ${ }^{113 \mathrm{~m}}$ In $(393 \mathrm{keV})$. The fraction of counts in the ${ }^{113 \mathrm{~m}} \mathrm{In}$ window that scattered into the technetium$99 \mathrm{~m}$ window was $21 \%$.

\section{EFFECTS OF TISSUE ATTENUATION}

Figure 2 illustrates typical solid retention histograms before and after correction of the data for tissue attenuation. In the interval from eight to 16 minutes there was a fall in count rate of $20 \%$ in the uncorrected data as food redistributed within the stomach. This fall was entirely attributable to radionuclide moving away from the collimator surface while remaining within the stomach (Fig. 3). In the following 16 minutes, as there was little redistribution of solid food, the count rate remained constant. The application of line correction factors

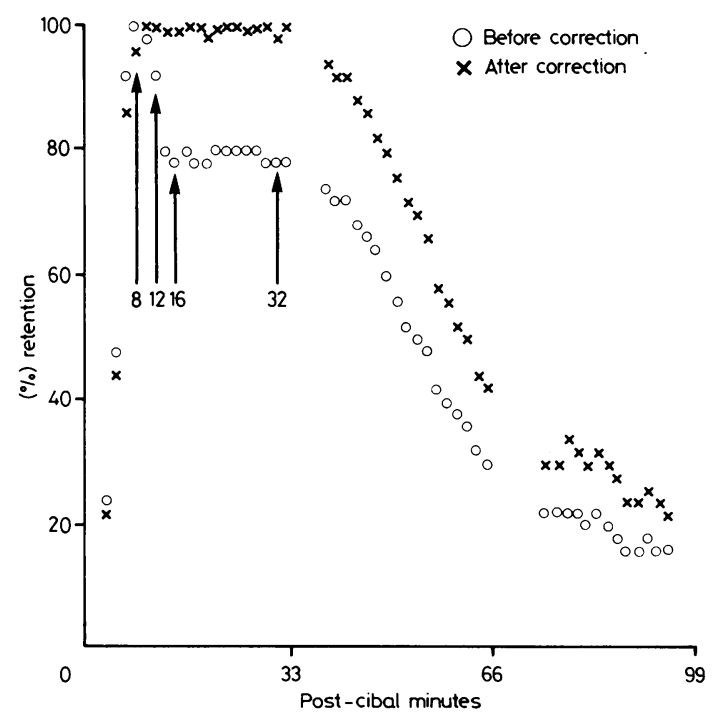

Fig. 2 Gastric emptying of ${ }^{99 m}$ Tc-labelled liver before ( $(0)$ and after $(X)$ correction for tissue attentuation in control subject. Arrows indicate percentage remaining in stomach at $8,12,16$, and 32 minutes. One hundred per cent retention is derived from the maximum count achieved in first 20 minutes of study. 


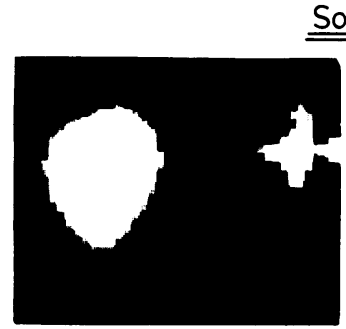

$8 \mathrm{~min}$

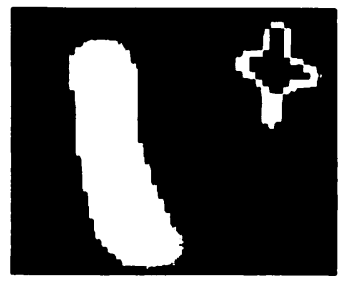

$16 \min$

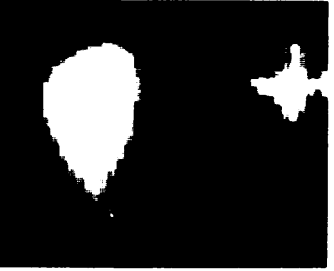

$12 \min$

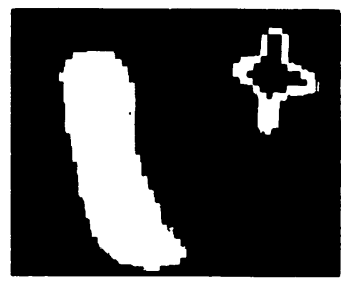

$32 \mathrm{~min}$
Fig. 3 Scintiphotos showing the distribution of solid ${ }^{99 m}$ Tc-liver) in stomach of control subject at $8,12,16$, and 32 minutes.

to the data eliminated the apparent emptying of food from the stomach. The resulting pattern showed a lag period before emptying (when food moved from the fundus to the antrum) followed by a linear emptying phase. In this study $\mathrm{T}_{50}$ changed from 49 minutes to 58 minutes $(16 \%)$ as a result of correction.

Tissue attenuation effects were less marked for liquids, reflecting the higher energy of ${ }^{113 \mathrm{~m}} \mathrm{In}$ (Fig. 4). Correction altered the $T_{50}$ from 19 minutes to 21 minutes $(10 \%)$.

In the 24 normal controls, the mean percentage increase in $\mathrm{T}_{50}$ values after correction was $22 \%$ for solid and $17 \%$ for liquid (Table 1 ).

\section{SOLID EMPTYING}

In all subjects solid emptied more slowly than liquid and was characterised by a lag period of variable duration followed by linear emptying (Fig. 5). The solid lag period was prolonged by the presence of both $10 \%$ and $25 \%$ dextrose in the liquid phase $(\mathrm{p}<0.01)$. The $\mathrm{T}_{50}$ value for solid was increased by $25 \%$ dextrose $(\mathrm{p}<0.025)$ but not by $10 \%$ dextrose. There was no difference between the three groups in the rate of linear emptying after the lag period (Table 2), and the delay of $\mathrm{T}_{50}$ with $25 \%$ dextrose reflected lengthening of the lag period.

LIQUID EMPTYING

The emptying of liquid was non-linear and usually

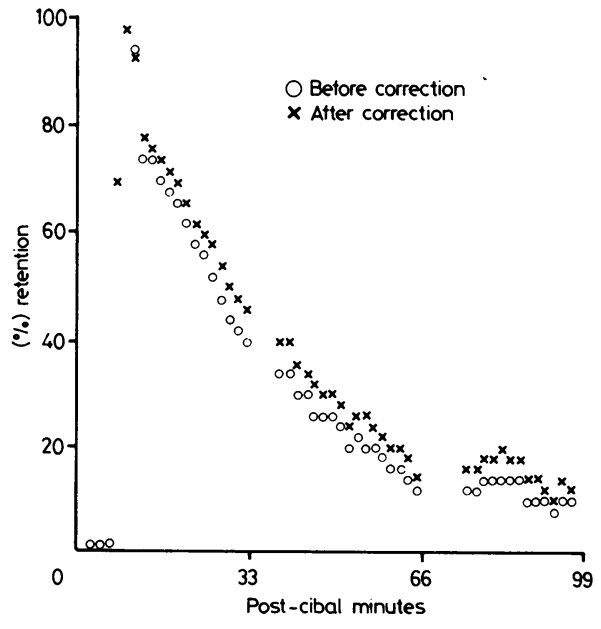

Fig. 4 Gastric emptying of liquid $\left({ }^{113 m}\right.$ In-DTPA) before $(0)$ and after $(X)$ correction for tissue attenuation in control subject.

followed a monoexponential pattern with minimal observable lag period (Fig. 5). Twenty five per cent dextrose delayed the $\mathrm{T}_{50}(\mathrm{p}<0.025)$ while with $10 \%$ dextrose this parameter was not significantly altered (Table 2). The amount of liquid remaining at 10 minutes was increased by both $10 \%$ dextrose and $25 \%$ dextrose $(\mathrm{p}<0.025)$.

There was a positive correlation between $T_{50}$ for liquid and $T_{50}$ for solid in all groups $(r=0 \cdot 65)$. For the three groups the length of the lag period correlated directly with the liquid $T_{50}(r=0.75$, $\mathrm{p}<0.001)$.

\section{RATE OF DELIVERY OF CALORIES TO THE DUODENUM}

The total number of calories (solid and liquid) delivered to the duodenum at varying time intervals in the first 50 minutes of the emptying study are shown in Table 3 . In both the solid and $10 \%$

Table 1 Effect of attenuation correction on solid and liquid $T_{50}$

\begin{tabular}{|c|c|c|}
\hline & Difference $=$ & $\frac{\text { Post-pre }}{\text { post }} \times 100 \%$ \\
\hline $\begin{array}{l}\text { Solid }\left({ }^{99 m} \mathrm{Tc}\right) \\
\text { Liquid }\left({ }^{113 m} \mathrm{In}\right)\end{array}$ & & $\begin{array}{l}=22(7-65) \\
=17(0-59)\end{array}$ \\
\hline
\end{tabular}

Values indicate mean values and range of 24 control subjects. 
Fig. 5 Effect of increasing liquid calorie content on liquid (a) and solid (b) emptying. Liquid meal was either water $(\Delta), 10 \%$ dextrose solution (ㅁ), or $25 \%$ dextrose solution (ם).

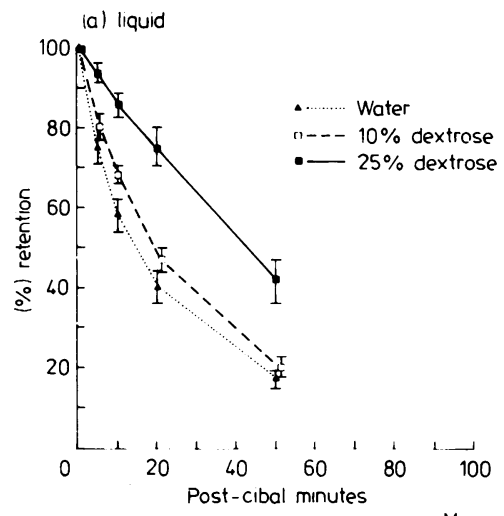

Mean values \pm SEM

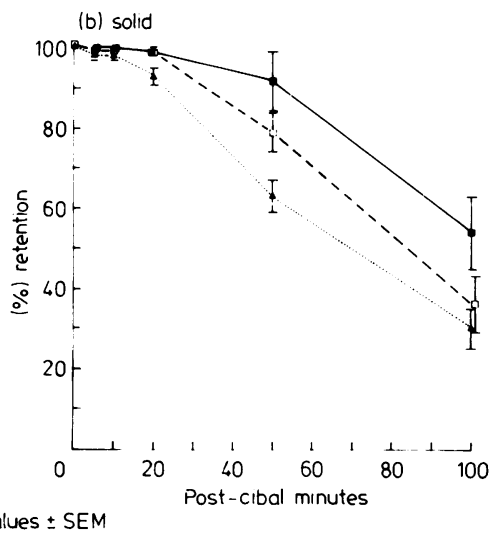

dextrose group and the solid and $25 \%$ dextrose group, approximately $110 \mathrm{kcal}(462 \mathrm{Kj}) \mathrm{had}$ left the stomach at 50 minutes. In the group of subjects who had received solid and water, the rate of delivery of calories was significantly slower (approximately 72 $\mathrm{kcal}(302 \mathrm{Kj})$ at 50 minutes $)$.

\section{REPRODUCIBILITY}

The reproducibility data for the parameters solid and liquid $\mathrm{T}_{50}$, solid lag period, and solid linear rate are illustrated in Fig. 6. A wide variation between the subjects exists for these parameters. There was significant correlation between day 1 and day 2 $(p<0.01)$ for the first three parameters $(r=0 \cdot 82$, $0.76,0.78$, repectively). The correlation coefficient for the solid linear rate was of borderline significance $(r=0.41,0.05<p<0 \cdot 10)$. The analysis of variance result is illustrated in Table 4 . The day-today variation (day effect) was not significant $(p>0.05)$ for any of the four parameters: solid and liquid $\mathrm{T}_{50}$, solid lag period, and solid linear rate. The variation between subjects and groups was significant for all parameters $(p<0.05)$ except the solid linear rate, where the between subject

Table 2 Effect of increasing the liquid calorie content on solid and liquid emptying

\begin{tabular}{llll}
\hline & Water & $\begin{array}{l}10 \% \\
\text { dextrose }\end{array}$ & $\begin{array}{l}25 \% \\
\text { dextrose }\end{array}$ \\
\hline Number of subjects & 11 & 7 & 6 \\
Solid lag period (min) & $21 \pm 2$ & $37 \pm 6$ & $60 \pm 9$ \\
Solid linear rate $\left(\% \mathrm{~min}^{-1}\right)$ & $1 \cdot 1 \pm 0 \cdot 1$ & $1 \cdot 2 \pm 0 \cdot 1$ & $1 \cdot 2 \pm 0 \cdot 1$ \\
Solid $T_{50}(\min )$ & $70 \pm 7$ & $78 \pm 8$ & $105 \pm 13$ \\
Liquid $\mathrm{T}_{5}$ & $15 \pm 2$ & $20 \pm 2$ & $46 \pm 7$ \\
Liquid retention after & $58 \pm 4$ & $68 \pm 2$ & $86 \pm 3$ \\
\hline
\end{tabular}

Data are mean values \pm SEM variation was of only borderline significance $(0 \cdot 05<p<0 \cdot 10)$. This variability of the data implies that three paired studies would be needed to detect a difference in gastric emptying time (solid $\mathrm{T}_{50}$ ) of $30 \%$, five for a difference of $20 \%$, and 19 for a difference of $10 \%(p=0.05)$.

\section{Discussion}

Previous workers have corrected for tissue attenuation in gastric emptying studies by using the geometric mean of counts taken at regular intervals in the anterior and posterior projections. ${ }^{9}{ }^{10}$ Tothill et $a^{10}$ scanned the patient at regular intervals $(10$, $30,60,90,120$ minutes) with a dual detector scanner, while Christian et al ${ }^{9}$ imaged at 30 minute intervals with a single scintillation camera. The effectiveness of the scintillation camera in mapping distribution changes within the stomach, however, is reduced if data are sampled infrequently.

Our studies indicate that adequate attenuation correction factors may be derived from a lateral image of the stomach. The use of these correction factors enables continuous monitoring of both solid

Table 3 Effect of increasing the liquid calorie content on the rate of delivery of calories (solid and liquid) to the duodenum

\begin{tabular}{llll}
\hline \multirow{2}{*}{\begin{tabular}{l} 
Time after $\begin{array}{l}\text { meal completion } \\
\text { (min) }\end{array}$ \\
\cline { 2 - 4 }
\end{tabular}} & Wotal calories* $($ Kcal $)+$ delivered \\
\cline { 2 - 4 } & 1 & $10 \%$ dextrose & $25 \%$ dextrose \\
\hline 5 & 2 & 16 & 10 \\
10 & 16 & 23 & 22 \\
20 & 72 & 36 & 40 \\
50 & 111 & 109 \\
\hline Mean values. & & & \\
+1 Kcal $=4 \cdot 2 \mathrm{Kj}$. & &
\end{tabular}


Solid emptying lag period (minutes)

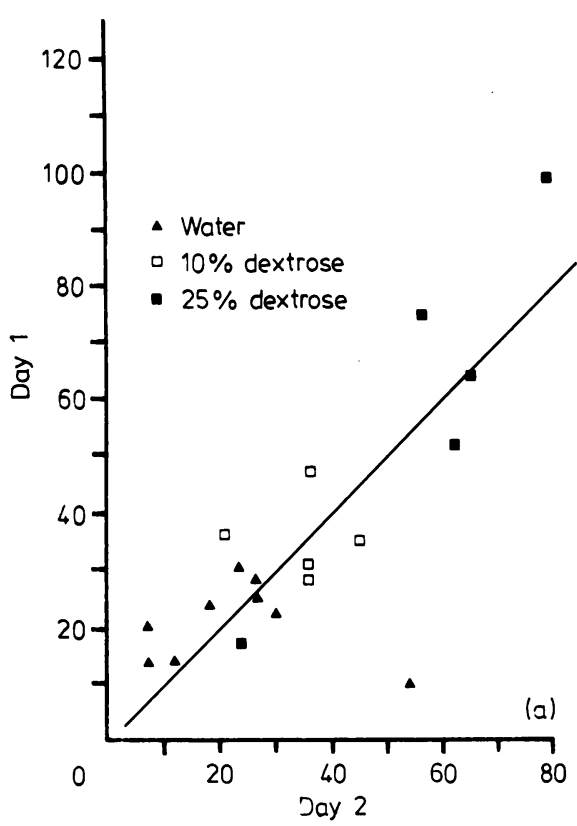

Solid emptying linear emptying rate (percent per minute)

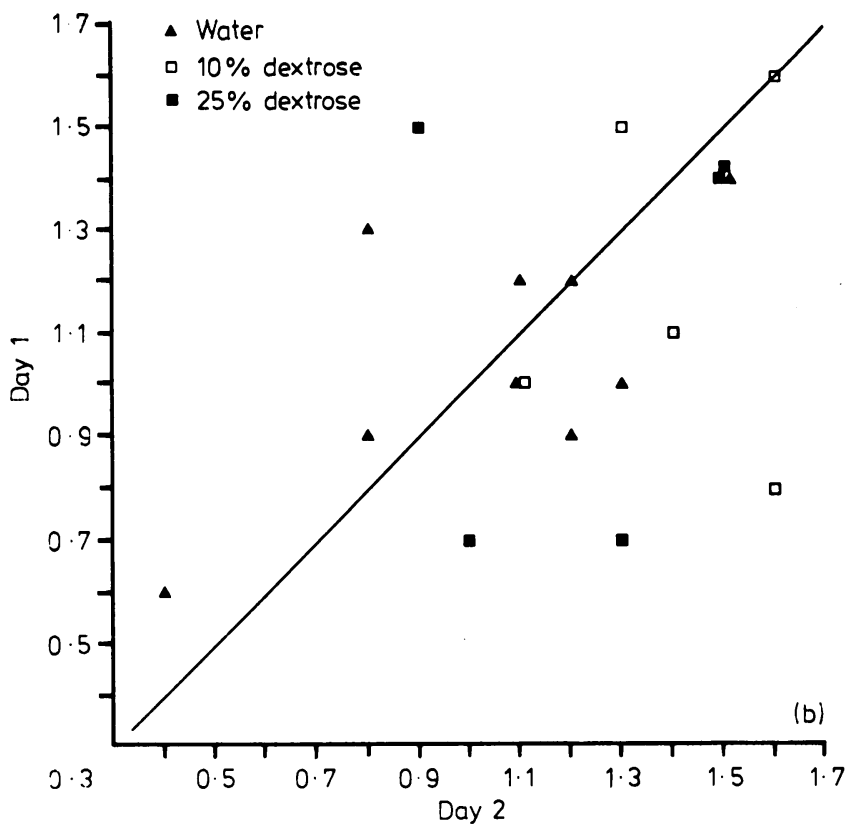

Solid emptying time tor $50 \%$ emptying (minutes)

Liquid emptying time for $50 \%$ emptying (minutes)
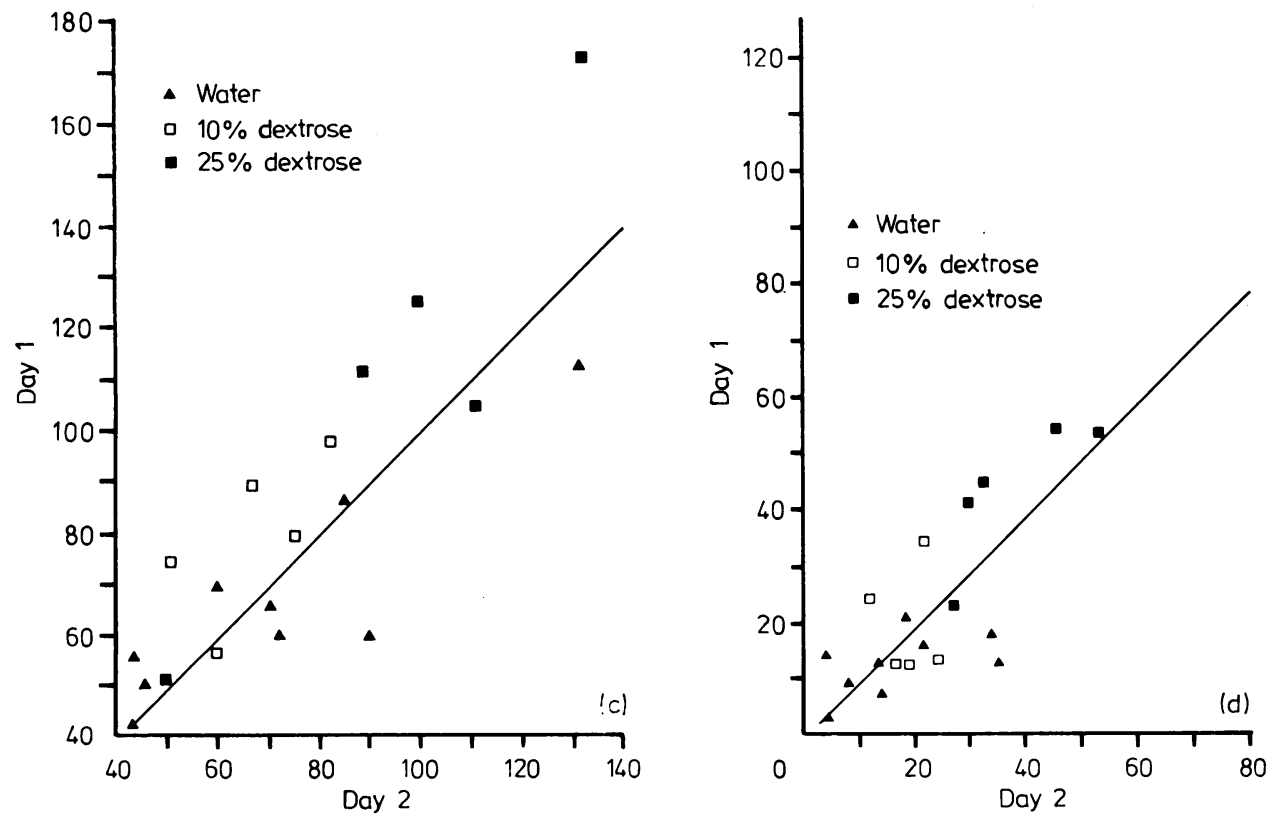

Fig. 6 (a-d) Reproducibility of gastric emptying in normal subjects. Data were obtained on two separate days and are plotted around line of identity (day $1=$ day 2). The parameters illustrated are (a) solid lag period; (b) solid linear rate; (c) solid $T_{\text {so; }}\left(\right.$ d) liquid $T_{\text {so. }}$ 
Table 4 Assessment of reproducibility using analysis of variance

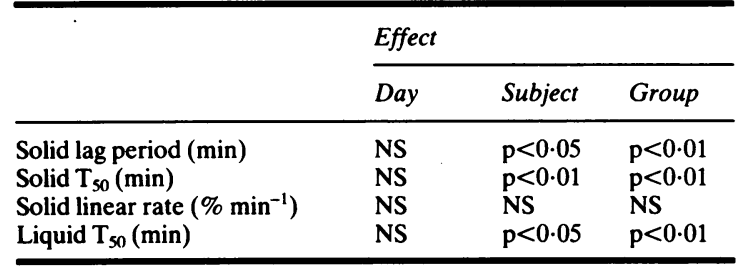

NS $=$ not significant $(p>0.05)$.

and liquid emptying using a single scintillation detector. An accurate estimate of the time of initial emptying of food and of the shape of the emptying curve can usually be obtained from the corrected data. In approximately $20 \%$ of patients, however, the shape of the stomach results in movement of food perpendicular to the detector and the correction is less effective. This usually occurred in the proximal stomach, resulting in a fall in count rate in the corrected data in the early part of the study of solid emptying, even though there was no evidence of food leaving the stomach (determined by visual inspection of the images). We have attempted to minimise this error by ignoring small changes in count rate in the first 15 minutes and taking the value after that time as the $100 \%$ retention value.

Significant error in the measurement of gastric emptying rate without attenuation correction can be inferred from the pre- and postcorrection $\mathrm{T}_{50}$ values obtained for solids and liquids (Table 1). The difference between pre- and postcorrection values are similar to those reported by Tothill $e t a l^{10}$ using the rectilinear scanner. Despite this, some groups have made no attempt to correct for attenuation. ${ }^{4} 1112$

The contribution of Compton scatter to the lower energy isotope in dual tracer studies can be minimised by using relatively lower quantities of the high energy tracer. ${ }^{9}$ In many gastric emptying studies, however, larger amounts of higher energy tracer are used to achieve good temporal resolution and correction factors must be applied. In phantom studies, Weiner et $\mathbf{a l}^{13}$ found that the percentage of downscatter from ${ }^{113 \mathrm{~m}} \mathrm{In}$ into the ${ }^{99 \mathrm{~m}} \mathrm{Tc}$ window ranged from $39 \%$ (fixed region of interest) to $74 \%$, when downscatter was considered in the whole field of view. The latter figure is of interest only if the percentage remaining in the stomach is calculated as a fraction of the total abdominal activity. Our phantom studies using a fixed region of interest did not confirm their result. Rapid time sampling in the first 10 minutes (five second store every 10 seconds) enabled our correction to be tested in patient studies, and no significant change was observed in the solid count rate as liquid entered the stomach. Because of the faster emptying of the liquid component (high energy nuclide) from the stomach, this correction is mainly required during the lag period of the solid study.

In the normal stomach, emptying of solid food is preceded by antral propulsive and retropulsive mincing, the end point being the passage into the duodenum of small particles $<1 \mathrm{~mm}$ in size. ${ }^{4} \mathrm{We}$ found that solid emptied in a linear pattern after an initial lag period in accordance with the findings of other authors. ${ }^{41214}$ The lag period before food enters the duodenum reflects both redistribution of food from fundus to antrum and the time taken to reduce some solid food to small particles. It is therefore dependent on fundal tone, stomach volume, and antral motility. Linear emptying probably occurs because of the ability of the antrum to maintain a relatively constant volume during emptying. ${ }^{814}$

The main factor controlling the emptying of liquids is the pressure gradient across the gastroduodenal junction which is largely dependent on fundal tone. ${ }^{15} 16$ Our observation that liquid emptying is an exponential or volume-dependent process has been reported by other investigators and is consistent with this postulate.

In mixed solid-liquid meals, liquids have been observed to empty more rapidly than solid, and a correlation between the rates of solid and liquid emptying has previously been noted. ${ }^{3} 14$

The rate of gastric emptying for both solids and liquids is also determined in part by the composition of the duodenal content. Previous investigators, using non-isotopic meals, have shown that gastric emptying slows with increasing calorie content of a liquid meal, and that this delay is mediated by duodenal receptors. ${ }^{17-20}$ In primates ${ }^{19}$ and in humans ${ }^{20}$ solutions of carbohydrate, protein, and fat slow gastric emptying in direct proportion to their calorie concentration in the range $0 \cdot 2-1 \mathrm{kcal} /$ $\mathrm{ml}(0.84-4.2 \mathrm{Kj} / \mathrm{ml})$, so that the rate of delivery of energy to the duodenum is maintained at a constant level. The slowing of gastric emptying may be mediated by the osmotic effects ${ }^{17-19}$ or alterations in calcium binding ${ }^{21}$ produced in the duodenum by the digestion products of food.

In this study, the progressive increase in calorie content of the liquid meal from 0 to 0.4 to $1 \mathrm{kcal} / \mathrm{ml}$ (0 to 1.7 to $4.2 \mathrm{Kj} / \mathrm{ml}$ ) resulted in a delay in both solid and liquid emptying. For liquids, a generalised slowing of the entire emptying curve was evident, while the delay in solid emptying reflected a lengthening of the lag period, with no alteration in the rate of linear emptying. 
The delay in liquid emptying with increasing calorie content of the liquid meal is consistent with an inhibitory effect mediated by duodenal receptors. As increasing the liquid calorie also delayed the redistribution of solid food from fundus to antrum (without altering the rate of linear emptying), it is likely that the delay of both solid and liquid emptying reflects a reduction in fundal tone mediated by duodenal receptors. The direct relationship between the liquid $\mathrm{T}_{50}$ and the duration of the lag period supports this hypothesis.

In this study of mixed solid and liquid meal, the rate of delivery of calories to the duodenum was approximately $2 \cdot 2 \mathrm{kcal} / \mathrm{min}(9.2 \mathrm{Kj} / \mathrm{min})$ in the two groups when liquid calories were given with the solid food. This result is similar to that previously obtained with liquid meals. ${ }^{20}$ In the group of patients who received water, calories entered the duodenum only after the solid lag period, partly accounting for the slower initial delivery of calories in this group.

There have been no published reproducibility studies using ${ }^{113 \mathrm{~m}}$ In-DTPA and ${ }^{99 \mathrm{~m}} \mathrm{Tc}-\mathrm{SC}$ to measure gastric emptying. Previous reproducibility studies using other radionuclides in normal subjects have shown day-to-day variation in gastric emptying rates within normal subjects, as well as wide variations in rates between subjects. ${ }^{13822}$ In this study, the day-to-day variation in gastric emptying within individual subjects was not significant compared with the variation between subjects in each group and did not affect the sensitivity of the technique in its ability to discriminate between the three groups studied.

Dr M Horowitz was supported by a grant from the National Health and Medical Research Council of Australia. We wish to thank Dr B W Gabb for his assistance with the statistical analysis.

\section{References}

1 Chandhuri TK. Use of ${ }^{99 m}$ Tc-DTPA for measuring gastric emptying time. J Nucl Med 1974; 15: 391-5.

2 Heading RC, Tothill P, Laidlaw AJ, Shearman DJC. An evaluation of ${ }^{113 \mathrm{~m}}$ In DTPA chelate in the measurement of gastric emptying by scintiscanning. Gut 1971; 12: 611-5.

3 Heading RC, Tothill P, McLoughlin GP, Shearman DJC. Gastric emptying rate measurement in man. A double isotope scanning technique for simultaneous study of liquid and solid components of a meal. Gastroenterology 1976; 71: 45-50.

4 Meyer JH, MacGregor IL, Gueller R, Martin P, Cavalieri R. ${ }^{99 \mathrm{~m}} \mathrm{Tc}$-tagged chicken liver as a marker of solid food in the human stomach. Am J Dig Dis 1976; 21: 296-304.

5 Horowitz $M$, Collins $P$, Cook DJ, Harding $P$, Shearman DJC. The effect of variation of the concentration of dextrose on the emptying of a mixed liquid and solid meal. [Abstract.] Gastroenterology 1982; 82: 1087.

6 Horowitz M, Cook DJ, Collins PJ, Harding PE, Hooper MJ, Walsh JF, Shearman DJC. Measurement of gastric emptying after gastric bypass surgery using radionuclides. $\mathrm{Br} J$ Surg 1982; 69: 655-7.

7 Horowitz M, Cook DJ, Collins PJ, Harding PE, Shearman DJC. The application of techniques using radionuclides to the study of gastric emptying. Surg Gynecol Obstet 1982; 155: 737-44.

8 Sheiner HJ, Quinlan MF, Thompson IJ. Gastric motility and emptying in normal and post-vagotomy subjects. Gut 1980; 21: 753-9.

9 Christian PE, Moore JG, Sorenson JA, Coleman RE, Weich DM. Effects of meal size and correction technique on gastric emptying time: studies with two tracers and opposed detectors. J Nucl Med 1980; 21: 883-5.

10 Tothill P, McLoughlin GP, Heading RC. Techniques and errors in scintigraphic measurements of gastric emptying. J Nucl Med 1978; 19: 256-61.

11 MacGregor IL, Martin P, Meyer JH. Gastric emptying of solid food in normal man and after subtotal gastrectomy and truncal vagotomy with pyloroplasty. Gastroenterology 1977; 72: 206-11.

12 Lavigne ME, Wiley ZD, Meyer JH, Martin P, MacGregor IL. Gastric emptying rates of solid food in relation to body size. Gastroenterology 1978; 74: $1258-60$.

13 Weiner K, Graham LS, Reedy T, Elashoff J, Meyer JH. Simultaneous gastric emptying of two solid foods. Gastroenterology 1981; 81: 257-66.

14 Moore JG, Christian PE, Coleman RE. Gastric emptying of varying meal weight and composition in man. Evaluation by dual liquid- and solid-phase isotopic method. Dig Dis Sci 1981; 26: 16-22.

15 Wilbur BG, Kelly KA. Effect of proximal gastric, complete gastric and truncal vagotomy on canine gastric electrical activity, motility and emptying. Ann Surg 1973; 178: 295-303.

16 Kelly KA. Gastric emptying of liquids and solids: roles of proximal and distal stomach. Am J Physiol 1980; 239: G71-6.

17 Hunt JN, Stubbs DF. The volume and energy content of meals as determinants of gastric emptying. J Physiol 1975; 245: 209-25.

18 Hunt JN, Cash R, Newland P. Energy density of food, gastric emptying and obesity. Am J Clin Nutr 1978; 31: S259-60.

19 McHugh PR, Moran TH. Calories and gastric emptying: a regulatory capacity with implications for feeding. Am J Physiol 1979; 236: R254-60. 
20 Brener W. Hendrix TR, McHugh PR. Intraduodenal glucose calories control gastric emptying in man. [Abstract.] Gastroenterology 1981; 80: 1116.

21 Hunt JN, McHugh PR. Does calcium mediate the slowing of gastric emptying in primates? Am J Physiol
1982; 243: G200-3.

22 Calderon M, Sonnemaker RE, Hersh T, Burdine JA. ${ }^{99 \mathrm{~m}} \mathrm{Tc}$-human albumin microspheres (HAM) for measuring the rate of gastric emptying. Radiology 1971; 101: 371-4. 